\title{
E-LEARNING MENYANGKUT EMPAT KETERAMPILAN BERBAHASA DALAM MATERI TEKS PIDATO
}

\author{
Ayu Alrahmi Putri \\ E-mail: ayualrahmiip@gmail.com \\ Program Studi Pendidikan Bahasa dan Sastra Indonesia, Universitas Riau
}

\section{Pengantar}

Bahasa merupakan alat komunikasi yang diucap dan didengarkan dalam kehidupan masyarakat. Bahasa sendiri adalah salah satu aspek yang sangat penting dalam kehidupan kita karena dengan adanya bahasa maka kita bisa menyampaikan tujuan atau maksud yang ingin kita berikan kepada orang lain. Bahasa juga dapat dikatakan sebagai media berekspresi seseorang yang mana ketika kita berbahasa atau menyampaikan maksud dan tujuan kita, maka akan diikuti dengan ekspresi guna untuk lebih memudahkan lagi dalam penyampaian informasi tersebut. Berbahasa merupakan salah satu keterampilan kegiatan komunikatif dalam rangka menjalin hubungan dengan lingkungan sosial dan sekitar.

(Tarigan, 2008) berpendapat bahwa keterampilan berbahasa mempunyai empat komponen, yaitu keterampilan menyimak (listening skills), keterampilan berbicara (speaking skills), keterampilan membaca (reading skills), keterampilan menulis (writing skills).

Yang mana keterampilan membaca dan menyimak merupakan keterampilan berbahasa yang bersifat kemampuan reseptif (decode) yakni proses yang berlangsung pada pendengar yang menerima kode-kode bahasa yang bermakna dan berguna yang disampaikan oleh pembicara melalui alat-alat artikulasi dan diterima melalui alat pendengar (Chaer, 2003). Sedangkan keterampilan berbicara dan menulis merupakan keterampilan berbahasa yang bersifat kemampuan produktif (encode) yang merupakan proses rancangan berbahasa (Chaer, 2003). Salah satu tindakan yang bisa saja menggunakan empat 
keterampilan berbahasa yakni keterampilan membaca, menyimak, menulis, dan berbicara adalah kegiatan pembelajaran mengenai materi 'Teks pidato'.

Teks pidato merupakan salah satu materi dalam pelajaran Bahasa Indonesia baik tingkat SD, SMP, dan SMA yang tiap tingkatannya memiliki kategori dan kesulitannya masing-masing. Yang mana dalam melakukan kegiatan pembelajaran Bahasa Indonesia tersebut perlu memperhatikan prinsip prinsip berupa, memandang bahasa sebagai teks bukan sekedar hanya kumpulan kata, penggunaan bahasa merupakan sebuah proses untuk memilih bentuk bahasa dalam mengungkapan makna tertentu, penggunaan bahasa tidak bisa dipisahkan dari konteks tertentu karena bahasa untuk mencerminkan ide atau sikap, dan bahasa adalah sarana dalam proses berpikir setiap manusia.

Sehingga (Khair, 2018) menuliskan bahwa kegiatan guru haruslah berupa menjelaskan dan menerapkan teks secara bersama-sama sampai dengan membuat teks secara individu. Hal tersebut adalah upaya untuk membuat pikiran siswa menjadi kreatif dan melatih agar lebih terstruktur dalam berbahasa.

Namun pada kenyataannya, pembelajaran daring di tingkat SMA dengan materi 'Teks pidato' dalam pelajaran Bahasa Indonesia biasanya hanya dilakukan dengan guru menjelaskan dan memberikan materi seperti pengertian, ciri, dan unsur dari teks pidato itu sendiri atau bisa juga dengan hanya memberikan tugas untuk mencari informasi umum mengenai teks pidato. Sehingga terkadang guru tidak memberikan kesempatan kepada muridnya untuk bisa membuat teks pidato sendiri lalu diikuti dengan kegiatan tampil di hadapan teman-temannya guna membacakan teks pidato yang mereka tulis.

Bahkan guru cenderung lebih mengabaikan aktivitas kegiatan yang melibatkan keterampilan berbicara muridnya yakni, seperti tidak memberikan kesempatan pada murid untuk tampil dihadapan teman sekelasnya untuk membacakan teks pidato yang mereka buat sendiri. Hal itu bersesuaian dengan penelitian (Sarono, 2002) yang menyatakan bahwa guru kurang memberi perhatian khusus pada pembelajaran bercerita. Penelitian tersebut diperkuat oleh 
pendapat (Galda, 2005) yang menyebutkan bahwa guru hanya memberikan perhatian sedikit pada aspek pengembangan bahasa lisan/berbicara.

(Subakti, 2020) menyatakan bahwa pembelajaran Bahasa Indonesia harus dapat dimaksimalkan dalam masa pandemi seperti ini walaupun dalam pembelajaran daring. Hal ini dapat dilakukan dengan cara memberikan pemahaman secara utuh kepada peserta didik. (Subakti, 2019) memberikan pemahaman tentang pelajaran Bahasa Indonesia yang harus dilakukan dengan saksama dan sungguh-sungguh.

Meskipun secara daring, pembelajaran bahasa Indonesia dalam materi 'Teks Pidato' yang dilakukan dengan seksama dan sungguh-sungguh itu dapat dilakukan dengan sebuah inovasi dimana murid membuat teks pidato sendiri lalu menampilkannya di hadapan teman-temannya dapat melatih serta meningkatkan keterampilan berbahasa si anak yakni berupa menulis, berbicara, menyimak, membaca, dan kreativitas si anak. (Sugono, 1993) juga mengatakan bahwa pembelajaran bahasa yang sebagai alat komunikasi akan menarik minat siswa karena siswa didesak oleh kebutuhannya untuk berkomunikasi dengan orang lain. Oleh karena itu, untuk memenuhi atau meningkatkan keterampilan menggunakan bahasa sebagai alat komunikasi itu, pembelajaran Bahasa Indonesia yang paling tepat adalah kegiatan dengan melibatkan seluruh keterampilan berbahasa di peserta didik serta melibatkan seluruh siswa dalam kegiatan pembelajaran.

Tak hanya itu, aktivitas pembelajaran daring dengan inovasi yang satu ini akan membuat anak merasa lebih percaya diri dan lebih termotivasi untuk belajar sehingga bisa mencapai hasil yang maksimal pula. Siswa yang memiliki sikap dan motivasi belajar yang tinggi dapat menimbulkan intensitas belajar yang lebih tinggi juga. Sehingga dengan kata lain, aktivitas belajar siswa dapat meningkat juga jika sikap dan motivasi belajarnya juga meningkat. Para ahli telah sepakat bahwasanya sikap dan motivasi memberikan peranan yang penting dalam hasil belajar siswa, khususnya pada pelajaran Bahasa Indonesia (Zulhafizh, Atmazaki, \& Syahrul, 2013) 


\section{Tindakan yang Dilakukan}

\section{a. Guru memberikan tugas kepada tiap-tiap muridnya untuk membuat teks pidato dengan tema yang bebas}

Dalam tindakan yang satu ini, siswa bisa melatih keterampilan menulis dan kreativitas mereka dalam membuat teks pidato yang baik, bagus, dan sesuai dengan ketentuan. Tak hanya itu, kegiatan ini juga bisa membuat murid bisa mengeksplor lebih dalam lagi mengenai pengetahuan tentang pidato sehingga mereka bisa menjadi lebih paham pada materi tersebut. Apalagi mengingat bahwa mereka melakukannya secara sendiri sehingga tentu ingatannya bisa jauh bertahan lebih lama karena murid terlibat langsung dalam kegiatan mencari informasi tersebut.

Dalam kontek pedagogis dan profesional guru, pemahaman dan kemampuan guru dalam menyelenggarakan pembelajaran merupakan suatu yang spesial untuk siswanya (Zulhafizh, 2020). Setiap siswa yang belajar mengharapkan adanya pengalaman dan informasi yang mereka dapatkan dari kegiatan belajar mengajar. Sehingga seluruh rangkaian aktivitas yang didesain oleh guru merupakan satu bagian penting yang tidak dapat dipisahkan dari pengalaman yang akan didapat oleh siswa. (Nassaji, 2012) dan (Lightbown, 2000) mengingatkan bahwa guru harus tahu apa saja yang dilakukan dan tidak perlu dilakukan. Agar kegiatan belajar mengajar berjalan dengan baik dan lancar serta guru bisa memberikan yang terbaik kepada muridnya sehingga bisa tercapainya tujuan pembelajaran.

\section{b. Guru memberikan kesempatan kepada muridnya untuk tampil secara sukarela tanpa ditunjuk namun setiap siswa memiliki kesempatan untuk tampil}

Veloo (2011) menjelaskan bahwa sikap belajar yang positif akan menimbulkan perasaan ingin belajar, seterusnya dapat mendorong dan merangsang kemampuannya dalam menyelesaikan masalah dalam belajar. 
Tindakan yang satu ini bisa membuat suasana kelas menjadi lebih nyaman, meningkatnya kepercayaan diri serta murid merasa tidak tertekan karena tidak ditunjuk oleh gurunya untuk bisa tampil ke depan. Pada dasarnya, siswa cenderung lebih suka ketika kegiatan belajar itu tidak muncul yang namanya tindakan paksaan dari guru yang mengajarnya alias murid lebih menyukai dengan sistem 'sukarelawan' atau siapa yang mau, itulah yang maju. Tak hanya itu, dengan sistem 'sukarelawan' murid bahkan biasa cenderung untuk ingin tampil mengikuti apa yang temannya telah lakukan sehingga bisa mendorong dan merangsang kemampuan yang mereka miliki serta tercapainya tujuan dari pembelajaran. Sikap belajar positif ini juga akan mengarahkan pandangan siswa yang misalnya berupa menumbuhkan sikap menyukai dan cinta terhadap pelajaran Bahasa Indonesia, selalu mengulang-ulang pelajaran tersebut dan sebagainya (Zulhafizh, Atmazaki, \& Syahrul R, 2013).

\section{c. Penampilan murid yang berpidato}

Dalam kegiatan tampilnya murid untuk berpidato, secara tanpa sadar murid dilatih mengenai keterampilan berbicara agar bisa menyampaikan pidatonya dengan sangat baik sehingga para pendengar bisa memahami apa yang mereka sampaikan dan tidak timbul yang namanya kesalahan pemahaman. (Tambunan, 2018) menjelaskan bahwa pembelajaran berbicara merupakan pembelajaran yang penting untuk diajarkan dan tidak boleh diabaikan karena melalui pembelajaran tersebut siswa diharapkan mampu mengungkapkan/menyampaikan pikiran, pendapat, ide, gagasan, atau perasaannya dengan baik. Tak hanya itu, kreativitas siswa dapat juga dilatih dalam kegiatan ini dengan tujuan untuk membuat para pendengar dan penonton terfokus pada yang ia sampaikan.

\section{Sarana Pendukung}

\section{a. Laptop/Ponsel}

b. Jaringan

c. Kuota internet 
d. Google meet/Zoom

e. Google Classroom

f. WA/Telegram

g. Situs-situs bidang pendidikan

h. Buku

i. Pakar-pakar bidang pendidikan

j. Aplikasi berbasis pendidikan

Dalam kegiatan pembelajarn ini, bisa melibatkan seluruh aspek keterampilan yakni menulis, membaca, menyimak, dan berbicara.

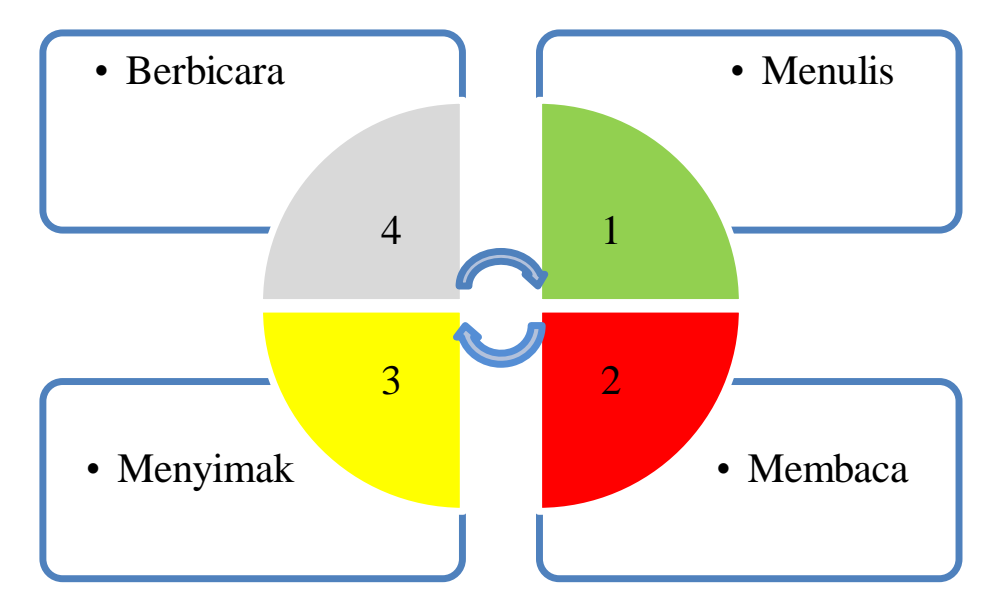

Gambar 1. Keterampilan menulis yakni berupa menulis teks pidato.

Gambar 2. Keterampilan membaca yakni berupa membaca teks pidato yang ditulis.

Gambar 3. Keterampilan menyimak yakni berupa mendengarkan penampilan teman yang tengah berpidato guna untuk mempelajari dan melihat bagaimana kita seharusnya bertindak saat berpidato.

Gambar 4. Keterampilan berbicara yakni berupa kegiatan berpidato di hadapan teman-teman sekelas dan guru mata pelajaran Bahasa Indonesia. 


\section{Tindakan Solutif}

a. Jika tidak ada laptop/ponsel, bisa meminjam laptop/ponsel orang lain dan bisa juga dengan membeli barang yang baru.

b. Jika jaringan kurang bagus, bisa mencari tempat yang jaringannya lebih bagus alias pindah lokasi dan mencari wifi gratis/warnet.

c. Jika tidak ada tempat atau lokasi yang jaringannya bagus, bisa dengan mengganti kartu paket dengan kartu yang jaringannya lebih bagus lagi sesuai dengan daerah tempat tinggal.

d. Jika zoom/google meet tidak bisa digunakan, maka bisa menggunakan Google classroom, WA, telegram, youtube, email, dan line.

e. Jika tidak bisa menemukan materi, maka bisa mencarinya di website pendidikan, buku, penelitian/pengamatan, dan bertanya kepada orang lain yang sekiranya bisa dijadikan tempat untuk bertanya.

\section{Simpulan}

Teks pidato dan berpidato merupakan salah satu materi dalam pelajaran Bahasa Indonesia baik tingkat SD, SMP, dan SMA yang tiap tingkatannya memiliki kategori dan kesulitannya masing-masing. Pada tingkat SMA, materi pidato dan berpidato dalam pelajaran Bahasa Indonesia biasanya hanya dilakukan dengan pemberian materi seperti pengertian, ciri, dan unsur dari pidato itu sendiri. Sehingga terkadang guru tidak memberikan kesempatan pada muridnya untuk bisa membuat teks pidato sendiri lalu diikuti dengan kegiatan tampil di hadapan teman-temannya guna membacakan teks pidato yang mereka tulis. Padahal tindakan pembelajaran dengan murid yang membuat teks pidato sendiri lalu menampilkannya di hadapan teman-temannya dapat melatih serta meningkatkan kemampuan menulis, berbicara, menyimak, membaca, dan kreativitas si anak.

Tak hanya itu, kegiatan ini juga bisa membuat murid bisa mengeksplor lebih dalam lagi mengenai pengetahuan tentang pidato sehingga mereka bisa menjadi lebih paham pada materi tersebut. Apalagi mengingat bahwa mereka melakukannya secara sendiri sehingga tentu ingatannya bisa jauh bertahan lebih lama karena murid terlibat langsung dalam kegiatan mencari informasi tersebut. 
Dan dalam kontek pedagogis dan profesional guru, pemahaman dan kemampuan guru dalam menyelenggarakan pembelajaran merupakan suatu yang spesial untuk siswanya. Setiap siswa yang belajar mengharapkan adanya pengalaman dan informasi yang ia dapatkan dari kegiatan belajar mengajar. 


\section{Referensi}

Chaer, Abdul. 2003. Psikolinguistik- Kajian Teoritik. Jakarta: Rineka Cipta.

Delvia. 2017. KOMPETENSI KOMUNIKATIF DALAM PEMBELAJARAN BAHASA.

Khair, U. (2018). Pembelajaran Bahasa Indonesia dan Sastra (BASASTRA) di SD dan MI. AR-RIAYAH : Jurnal Pendidikan Dasar, 2(1), 81. https://doi.org/10.29240/jpd.v2i1.261

Lightbown, P. M. (2000). Anniversary Article. Classroom SLA Research and Second Language Teaching. Applied linguistics, 21(4), 431-462.

Nassaji, H. (2012). The Relationship Between SLA Research and Language Pedagogy: Teachers' Perspectives. Language Teaching Research, 16(3), 337-365.

Sarono. 2002. "Keterampilan Berbicara." Makalah disajikan dalam Pelatihan Guru Sekolah Dasar Mata Pelajaran Bahasa Indonesia" Provinsi Jawa Tengah di Semarang

Subakti, Hani. (2019). 8 Konsepsi Landasan Bahasa Indonesia di Perguruan Tinggi. Parepare: Kaaffah Learning Center.

Subakti, Hani. (2020). Hasil Belajar Muatan Bahasa Indonesia Tema Peduli Terhadap Makhluk Hidup Menggunakan Reward Pada Kelas IV SDN 023 Samarinda Utara. Vol.03 No. 01, 1-9, Juni 2020. https://doi.org/10.36277/basataka.v3i1.80.

Suriyadi. 2013. Evaluasi Pembelajaran Bahasa Indonesia. Gorontalo: Universitas Negeri Gorontalo Press.

Sestya, Ajeng. 2020. INOVASI PEMBELAJARAN BAHASA INDONESIA MELALUI PENDEKATAN KOMUNIKATIF. 
Tambunan, P. (2018). Pembelajaran keterampilan berbicara di sekolah dasar. Jurnal Curere, 2(1).

Tarigan, H. G. 2008. Menulis sebagai Suatu Keterampilan Berbahasa. Bandung: Angkasa.

Veloo, Arsaythamby dan Shamsuddin Muhammad. 2011. - Hubungan Sikap, Kebimbangan, dan Ta-biat Pembelajaran dengan Pen-capaian Matematika Tamba-hanll. dalam Asia Pacific Journal of Educators and Education, Vol. 26, No. 1, hal. 15-32. Malaysia: Universitas Sains Malaysia.

Zulhafizh, Atmazaki, \& Syahrul R. (2013). Kontribusi Sikap dan Motivasi Belajar Siswa terhadap Hasil Belajar Bahasa Indonesia. Jurnal Bahasa, Sastra dan Pembelajaran, 1(2), 13-28.

Zulhafizh. (2020). Orientation on Implementation of Learning Curriculum at Senior High School: Teacher's Perspective. Jurnal PAJAR (Pendidikan dan Pengajaran), 4(2), 303-315. 


\section{*Data Penulis}

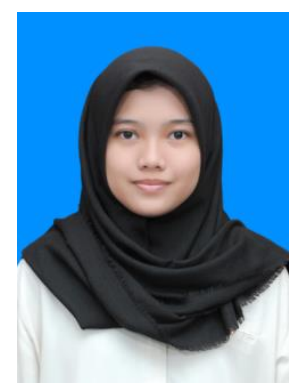

Ayu Alrahmi Putri, lahir di Pekanbaru, 16 Mei 2002. Tamatan dari SDN 75 Pekanbaru, SMP 1 Pekanbaru, dan SMAN 1 Pekanbaru yang pada tahun 2020 melanjutkan pendidikannya pada strata satu Jurusan Pendidikan Bahasa dan Seni di Program Studi Pendidikan Bahasa dan Sastra Indonesia FKIP Universitas Riau melalui jalur SBMPTN (Seleksi Masuk Bersama Perguruan Tinggi Nasional). Ayu — panggilan akrabnyamemang belum memiliki prestasi terkait dengan jurusannya saat ini. Namun, ketika SD, SMP, dan SMA prestasi Ayu hanya sekedar menjadi juara di kelas saja. Di sela-sela kesibukannya, Ayu merupakan sosok yang

cukup aktif dalam bidang tulis menulis di aplikasi bernama Wattpad. Hal itu dapat dibuktikan dengan empat cerita pendek yang sudah tamat serta satu novelnya yang saat ini masih dalam proses penulisan.

Untuk kedepannya, Ayu berharap agar di tahun 2022 ini ia bisa lolos dalam semua tahapan seleksi masuk sekolah kedinasan yang diinginkannya. Jika memang bukan rezekinya, maka Ayu berharap agar ia bisa lulus dalam waktu 3,5 tahun dengan nilai yang memuaskan dan dapat menerapkan ilmu-ilmu yang sudah ia dapatkan selama mengenyam pendidikan di strata satu Jurusan Pendidikan Bahasa dan Seni di Program Studi Pendidikan Bahasa dan Sastra Indonesia FKIP Universitas Riau. Ayu juga berharap agar nantinya karya-karya yang ia tulis bisa terbit dan terpajang gagah di seluruh toko buku di Indonesia serta bisa melanjutkan pendidikan ke strata dua dan tiga sehingga impiannya untuk menjadi dosen bisa terwujud.

Akhir kata penulis mengucapkan rasa syukur yang sebesar-besarnya atas terselesaikannya tugas UAS pada mata kuliah 'Inovasi Pendidikan' dengan sebuah artikel yang berjudul 'Inovasi Pembelajaran yang Melibatkan Empat Keterampilan Berbahasa dalam Materi Teks Pidato’.

Kontak:

Hp/WA : +6289621474860

Email : ayualrahmiip@gmail.com 